$\begin{array}{cl}\begin{array}{c}\text { Revue } \\ \text { de /histoire }\end{array} & \text { Revue de l'histoire des religions } \\ \text { des religions } & \begin{array}{l}3 \mid 2013 \\ \text { Varia }\end{array}\end{array}$

\title{
$\mathrm{La}(\mathrm{re})$ conversion des « esprits de la terre » dans
} l'Islande médiévale

(Re)converting Medieval Iceland's "Spirits of the Land"

\section{Nicolas Meylan}

\section{(2) OpenEdition \\ Journals}

Édition électronique

URL : http://journals.openedition.org/rhr/8121

DOI : $10.4000 /$ rhr.8121

ISSN : 2105-2573

Éditeur

Armand Colin

Édition imprimée

Date de publication : 1 septembre 2013

Pagination : 333-354

ISBN : 978-2200928650

ISSN : 0035-1423

Référence électronique

Nicolas Meylan, «La (re)conversion des « esprits de la terre » dans l'Islande médiévale », Revue de

I'histoire des religions [En ligne], 3 | 2013, mis en ligne le 01 septembre 2016, consulté le 19 avril 2019.

URL : http://journals.openedition.org/rhr/8121 ; DOI : 10.4000/rhr.8121 
NICOLAS MEYLAN

Universités de Genève et Lausanne

\section{La (re)conversion des «esprits de la terre» dans l'Islande médiévale}

Cet article se propose d'analyser les «esprits de la terre» (landvættir) de l'Islande médiévale non pas en vue de reconstituer une croyance scandinave préchrétienne mais afin de montrer que plus de deux siècles après la conversion, ces êtres mythologiques pouvaient être utilisés dans un discours politique établissant la capacité contemporaine de la communauté insulaire à se défendre alors que pesait sur l'île la menace d'une annexion norvégienne.

\section{(Re)converting Medieval Iceland's "Spirits of the Land".}

This article offers an analysis of Medieval Iceland's "spirits of the land" (landvættir) not with the aim of reconstructing a pre-Christian Scandinavian belief but rather to show that, more than two centuries after the conversion, these mythological beings could be used within a political discourse in order to establish the island's contemporary capacity to defend itself at a time when Iceland was threatened with Norwegian annexation. 


\section{I/ INTRODUCTION}

Les discussions savantes portant sur les «esprits de la terre» (landvattir, sing. landvattr) de l'Islande médiévale tendent à mettre en évidence leur nature et leur origine préchrétiennes. Ainsi figurent-ils régulièrement dans les dictionnaires de mythologie norroise (où l'équation entre mythe et paganisme est implicite) ${ }^{1}$ et dans les études portant sur la religion préchrétienne - notamment la vaste Altgermanische Religionsgeschichte de Jan de Vries, un texte qui fait autorité aujourd'hui encore ${ }^{2}$ - alors qu'ils sont absents des études portant sur le christianisme scandinave médiéval.

La ligne de partage définie par la conversion de l'an mil pose toutefois deux problèmes. D'une part, toutes les mentions écrites des landvattir appartiennent au contexte post-conversion. L'Église était responsable de l'introduction de l'écriture (exception faite des runes impropres aux textes narratifs) et les textes qui nous sont parvenus furent invariablement rédigés par des chrétiens à partir du milieu du XII ${ }^{\mathrm{e}}$ siècle. De ce fait, la reconstruction des croyances de la période précédant la conversion au moyen de tels écrits peut s'avérer quelque peu problématique. D'autre part, lorsque des spécialistes placent ces êtres dans le panthéon païen, ils les stabilisent au sein d'un système statique et leur donnent une signification unifiée et détachée de toute situation de communication. Dès lors, leur présence ne s'explique au mieux que par un intérêt antiquaire de la part des Scandinaves médiévaux; au pire, ils représentent une de ces survivances chères à Edward Burnett Tylor.

De ces deux observations, il découle que les énoncés relatifs aux landvaettir postérieurs à la conversion gagnent à être également analysés dans leur contexte de production, en posant les questions suivantes: qui parle? en lien avec qui? et à quelles fins? Dans ce qui suit, je soumettrai ces «esprits de la terre» (quelle terre? la

1. Voir, par exemple, Rudolf Simek, article «landvattir», Dictionary of Northern Mythology, Woodbridge, 1993, p. 186; Andy Orchard, article «landvattir», Cassell Dictionary of Norse Myth and Legend, London, 1998, p. 102103.

2. Jan de Vries, Altgermanische Religionsgeschichte, Berlin, t. 1, 1970, p. 260261. Ce texte a été publié pour la première fois entre 1935 et 1937. 
terre de qui ?) à une analyse qui indiquera que, malgré une origine indubitablement préchrétienne, ils se montrèrent fort utiles et décidément actifs dans la Scandinavie chrétienne.

\section{II/ L'ISLANDE DE 870, UNE ÎLE DÉSERTE?}

La Landnámabók (ou Livre de la colonisation) est une vaste compilation de matériaux généalogiques et narratifs faisant la chronique de la colonisation de l'Islande à partir de 870. Différentes versions médiévales de ce texte subsistent. La Landnámabók est ainsi préservée par trois manuscrits médiévaux islandais: Melabók dont ne survit qu'une page datant de 1400; Sturlubók (S) rédigée par Sturla Pórðarson (mort en 1284). Ces deux textes reprennent, avec des omissions, la version perdue de Styrmir Kárason (11701245), qui fut écrite vers 1220. Finalement, la Hauksbók (H) fut compilée par l'Islandais Hauk Erlendsson (mort en 1334) sur la base de S et de la version perdue de Styrmir (Styrmisbók) ainsi qu'il l'écrivit lui-même au chapitre CCCLIV de son livre 3 .

La Landnámabók débute par l'histoire de la découverte de l'île par un Norvégien du nom de Naddoð et se poursuit avec les premières tentatives de colonisation d'une Islande explicitement libre de propriétaires humains. En effet, bien que le livre fasse mention de la présence de reliques chrétiennes sur l'île, il note que celle-ci était déserte à l'arrivée des Scandinaves 4 . Ayant entendu des rumeurs de terres vierges, le Suédois Garðar Svavarsson partit pour l'île, mais

3. Au sujet de la Landnámabók, voir Jón Jóhannesson, Gerðir Landnámabókar, Reykjavík, 1941; Jakob Benediktsson, «Landnámabók: Some Remarks on Its Value as a Historical Source», Saga-Book, 17, 1966-69, p. 275-292; Sveinbjörn Rafnsson, Studier i Landnámabók. Kritiska bidrag till den isländska fristatstidens historia, Lund, 1974; Jakob Benediktsson, «Formáli», Íslendingabók. Landnámabók, éd. Jakob Benediktsson, Reykjavík (Íslenzk Fornrit, I), 1986, p. L-CLIV ; Jonas Wellendorf, «The Interplay of Pagan and Christian Traditions in Icelandic Settlement Myths », Journal of English and Germanic Philology, 109/1, 2010, p. 1-21.

4. Landámabók, chap. S III (in Íslendingabók. Landnámabók, éd. Jakob Benediktsson, Reykjavík (Íslenzk Fornrit, I), 1986, p. 34): «Peir gengu upp í Austfjörðum á fjall eitt hátt ok sásk um víða, ef peir sæi reyki eða nökkur líkindi til pess, at landit væri byggt, ok sá peir pat ekki.» ([Naddoð et ses hommes] escaladèrent une haute montagne dans les Fjords de l'Est et regardèrent loin à la ronde à la recherche de fumée ou de quelque signe que la terre était occupée, mais ils n'en virent aucun). 
non sans avoir auparavant reçu le consentement de sa mère dont le livre note les capacités divinatoires (framsýn). Il fut capable d'y passer l'hiver, mais, peut-être parce qu'il ne venait pas du bon pays, ne s'établit pas de façon permanente en Islande.

La perspective alléchante de territoires vierges appâta bientôt un autre viking, Floki Vilgerðarson. Avant d'embarquer, il fit un grand sacrifice durant lequel il consacra (blótaði) trois corbeaux. Une fois en pleine mer, ceux-ci devaient, en l'absence de cartes ou de points de repère, le guider vers l'Islande selon un mode opératoire qui ne va pas sans rappeler l'histoire de Noé cherchant une terre émergée (Gen. 8, 6-12). Plutôt imprévoyant, il ne fut pas capable de se maintenir durant l'hiver rigoureux de l'Atlantique nord et abandonna l'île qu'il baptisa amèrement Ísland («terre de glace $»)^{5}$.

C'est avec Ingólf Arnason, l'homme qui devait rester dans les mémoires comme le premier colon (landnámsmaðr), que la Landnámabók développe un thème sous-jacent dans les récits précédents, la nécessité de se doter d'un visa surnaturel pour accéder à l'île sans dommage, que ce soit sous la forme de la parole performative d'une devineresse ou du vol de corbeaux consacrés $^{6}$. Le récit met en place une opposition entre deux frères adoptifs norvégiens Ingólf et Hjörleif. Le premier «sacrifie» ( $f a ́$ at blóti) afin de connaître son destin, alors que le deuxième «ne voulait jamais sacrifier ${ }^{7}$. Lorsqu'Ingólf arrive en vue de l'île, il jette par-dessus bord les piliers de son haut siège et annonce qu'il s'établira à l'endroit où ils échoueront. Ainsi par deux fois, il se soumet à une volonté qui n'est pas la sienne - d'autres textes, dont le quatrième chapitre de l'Eyrbyggja saga, indiquent que ce serait celle du dieu Thor - et devient le fondateur d'une lignée fameuse. Cette pratique est suivie par nombre d'autres colons importants ${ }^{8}$.

5. Landámabók, chap. $\mathrm{S} \mathrm{v}$ et $\mathrm{H}$ v (in Íslendingabók. Landnámabók, op. cit., p. 36-39).

6. Pour une discussion récente de ce thème, voir Jonas Wellendorf, art. cit., p. 6-7.

7. Landnámabók, chap. S VII et H VII (in Íslendingabók. Landnámabók, op. cit., p. 42): «Hjörleifr vildi aldri blóta.»

8. Sur les «piliers du haut siège» (öndvegissúlur), on consultera Dag Strömbäck, «Att helga land», Festskrift tillagnad Axel Hagerstrom, Uppsala, 1928, p. 198220; Gabriel Turville-Petre, «Thurstable», Nine Norse Studies, London, 1972, p. 24-26; Jan De Vries, op. cit., t. 1, p. 382, et t. 2, p. 388-391. 
Hjörleif en revanche ne se fie qu'à lui-même, mais est tué par ses esclaves moins d'une année après son arrivée dans l'île. Cet épisode est interprété par Ingólf comme une conséquence directe de son irréligion ${ }^{9}$.

Plus de trois cent chapitres plus loin, la Landnámabók revient brièvement sur ces événements et laisse entrevoir la raison pour laquelle Hjörleif eut une fin aussi misérable: «Ölvir, fils d'Eystein, prit de la terre à l'est de la Grímsá; personne n'avait osé habiter là à cause des landvattir après que Hjörleif fut tué» ${ }^{10}$. Ce passage très lapidaire suggère deux remarques, l'une évidente, l'autre davantage sujette à caution. D'une part, l'Islande est représentée comme étant habitée par une population non-humaine, les landvattir, les «esprits ou êtres de la terre». D'autre part, ces derniers et la terre qu'ils occupent doivent être approchés avec des précautions rituelles, sacrificielles ou divinatoires, car ils peuvent nuire aux futurs colons.

\section{III/ Les LANDVATTIR}

Que, ou plutôt qui sont ces landvattir? Outre leur nom qui suggère un lien fort avec un territoire particulier (le substantif land peut en effet être utilisé pour désigner ce qui s'oppose à la mer, une propriété foncière ou encore un pays), quelques textes apportent des précisions sur leur nature et leurs fonctions ${ }^{11}$. Comme d'autres catégories mythologiques, dises, elfes et nornes

9. Landnámabók, chap. S VIII et $\mathrm{H}$ VIII (in Íslendingabók. Landnámabók, op. cit., p. 44) : «Lítit lagðisk hér fyrir góðan dreng, er prælar skyldu at bana verða, ok sé ek svá hverjum verða, ef eigi vill blóta.» (Un noble homme a eu une fin indigne: être tué par des esclaves; mais je pense qu'il en sera ainsi pour quiconque refuse de sacrifier).

10. Landnámabók, chap. S cCcxxx et H CCXc (in Ibid., p. 333): «Ölvir, son Eysteins nam land fyrir austan Grímsá; par hafði engi maðr porat at nema fyrir landvættum, síðan Hjörleifr var drepinn. »

11. Bien que les occurrences textuelles du terme soient peu nombreuses, ces êtres ont excité l'attention de nombreux savants, voir Strömbäck, op. cit.; Bo Almqvist, Norrön niddiktning, vol. 1, Nid mot furstar, Stockholm, 1965, p. 147154; Gabriel Turville-Petre, Myth and Religion of the North, Westport, 1975, p. 232-233; Jan de Vries, op. cit., t. 1, p. 260; Kirsten Hastrup, Culture and History in Medieval Iceland, Oxford, 1985, p. 143 et 188; Hilda Ellis Davidson, Myths and Symbols in Pagan Europe, Manchester, 1988, p. 103-104; Margaret Clunies Ross, Prolonged Echoes, Old Norse Myths in Medieval Northern Society, Odense, 1998, 
(dísir, álfar, nornir), les landvattir forment un groupe dénué d'individualité et par conséquent ne reçoivent pas de nom propre. Ils sont normalement invisibles et semblent demeurer, selon les lois du Gulaping (assemblée de la région du centre de la Norvège) rédigées dans la deuxième moitié $\mathrm{du} \mathrm{XIII}^{\mathrm{e}}$ siècle, dans les bosquets, dans les tertres ou encore dans les chutes d'eau ${ }^{12}$. Leur relation à un territoire peut englober la communauté humaine qui y vit, et cela de différentes manières. Outre le passage qui relate les suites du meurtre de Hjörleif, les landvattir apparaissent à deux autres endroits dans la Landnámabók. Dans le premier, ils jouent le rôle de pourvoyeurs de la fertilité.

Björn et ses frères ont été chassés de leurs terres par une coulée de lave, ils s'établissent à Grindavík mais disposent de peu de bétail. Toutefois, ils vont recevoir de l'aide:

Björn rêva une nuit qu'un habitant des pierres venait à lui et lui offrait de faire association et il rêva qu'il acceptait. Après cela, un bouc vint à ses chèvres, et son bétail prospéra tant qu'il devint rapidement riche. Il fut alors appelé Björn au bouc. Les gens doués de seconde vue virent que tous les landvattir accompagnaient Björn au bouc à l'assemblée et Pórstein et Pórð à la chasse et à la pèche ${ }^{13}$.

S'il ne fait pas de doute que les landvattir sont directement responsables de la bonne fortune des frères, l'histoire ne dit pas ce que Björn devait en échange des services de ceux-ci et de leur représentant désigné par le terme générique «l'habitant des pierres $»^{14}$. Toutefois, un autre texte donne une indication de ce qui pouvait

p. 22-157; Klaus Böldl, Eigi einhamr. Beiträge zum Weltbild der Eyrbyggja und anderer Isländersagas, Berlin, 2005, p. 154 sq.

12. Norges gamle love indtil 1387, éd. Rudolph Keyser et Peter Munch, Christiania, 1846, t. 2, p. 308: «En pæssir luttir heyra til villu ok hædins atrunaddar $[\ldots]$ ok at trua a landvættir at se i lundum æda haugum æda forsum.» (Et ces choses appartiennent à l'hérésie et à la religion païenne [...] et de croire que les landvattir sont dans les bosquets ou les tertres ou les chutes d'eau).

13. Landnámabók, chap. S CCCXXIX (in Íslendingabók. Landnámabók, op. cit., p. 330) : «Björn dreymði um nótt, at bergbúi kœmi at honum ok bauð at gera félag við hann, en hann póttisk játa pví. Eptir pat kom hafr til geita hans, ok tímgaðisk pá svá skjótt fé hans, at hann varð skjótt vellauðigr; síðan var hann Hafr-Björn kallaðr. Pat sá ófreskir menn, at landvættir allar fylgðu Hafr-Birni til pings, en peim Porsteini ok Pórði til veiða ok fiskjar.»

14. Le terme bergbúi qui insiste sur l'ancrage à un terroir, peut désigner d'autres types d'êtres mythologiques, en particulier les jötnar («géants»; cf. le poème de l'Edda Poétique, Hymiskviða strophe 2). Le portrait que donne le Bergbúa páttr (ou Court récit de l'habitant des pierres) est plus sinistre. Là, seuls les yeux luisants de l'habitant des pierres sont visibles alors qu'il énonce des vers 
être attendu de Björn. Une homélie conservée dans le manuscrit Hauksbók (1306-1308) dénonce les offrandes de nourriture faites à ces esprits par des femmes ${ }^{15}$. Si dans le cas présent il ne s'agit que d'une relation volontaire n'impliquant qu'une seule famille, le dernier passage de la Landnámabók les concernant suggère en revanche un lien entre ces êtres et la communauté islandaise dans son entier.

Le chapitre CCLXVIII de la version $\mathrm{H}$ de la Landnámabók, probablement sur la base de la version de la Styrmisbók (c. 1220) ${ }^{16}$, raconte qu'Úlfljót, un colon d'origine norvégienne, avait élaboré en Norvège autour de 920 un code de loi dans le but de construire la nouvelle communauté insulaire (lag, le mot a la même origine que lög «loi»). Le chapitre II de la Íslendingabók (ou Livre des Islandais), un bref texte historique écrit dans la première moitié du $\mathrm{XII}^{\mathrm{e}}$ siècle traitant de l'établissement de la «république» d'Islande, mentionne également les activités législatives d'Úlfljót et ajoute que ce dernier fonda en partie son travail sur l'ancêtre des lois du Gulaping mentionnées supra. La Landnámabók donne quelques indications sur ce que contenait son texte, en particulier que:

Le début des lois païennes était que les gens ne devaient pas avoir de navires à têtes en mer, et que s'ils en avaient, ils devaient en enlever les têtes avant d'arriver en vue des terres, et ne pas faire voile vers la terre avec des têtes béantes ou des gueules ouvertes, afin que les landvattir ne fussent pas terrorisés ${ }^{17}$.

Le texte représente ainsi la jeune communauté islandaise voyant d'un mauvais œil le fait d'effrayer les esprits de la terre au moyen

en galdralag, un mètre associé à la sorcellerie et aux prophéties de malheur. De plus, le bergbúi y est clairement lié au paganisme.

15. Cette homélie est partiellement dérivée d'un texte anglo-saxon. Il est intéressant de noter que le manuscrit où elle apparaît contient également une version de la Landnámabók (H). Voir Clunies Ross, op. cit., p. 137, n. 27; Ingjald Reichborn-Kjennerud, «Et Kapitel av Hauksbók», Maal og Minne, 1934, p. 144148.

16. Jakob Benediktsson (in Íslendingabók. Landnámabók, op. cit., p. 312-313, n. 8) estime probable que cette matière était présente dans la Melabók.

17. Landnámabók, chap. H cCLXVIII (in Íslendingabók. Landnámabók, op. cit., p. 313) : «Pat var upphaf hinna heiðnu laga, at menn skyldu eigi hafa höfuðskip í haf, en ef peir hefði, pá skyldi peir af taka höfuð áðr peir kœmi í landsýn, ok sigla eigi at landi með gapandi höfðum eða gínandi trjónum, svá at landvættir fælisk við.» Concernant ce texte, voir François-Xavier Dillmann, Les magiciens dans l'Islande ancienne. Études sur la représentation de la magie islandaise et de ses agents dans les sources littéraires norroises, Uppsala, 2006, p. 511, n. 26. 
des fameuses figures de proue des navires vikings, sculptées de sorte à ressembler à des dragons, des taureaux ou des chevaux menaçants ${ }^{18}$. Des figures de proue qui, selon des savants comme Margaret Clunies Ross et François-Xavier Dillmann, visaient à terrifier l'ennemi, landvattir selon ce texte, mais surtout humain comme l'atteste plus d'une description de bataille navale, dont la strophe suivante attribuée à Pórbjörn hornklofi (IX siècle) par la Haralds saga ins hárfagra (ou Saga du roi Harald à la belle chevelure, chap. XVIII, $c$. 1220): «Il entendit comment le noble roi à Hafrsfjord se battit contre Kjötvi le riche. Les navires vinrent de l'est, désireux de se battre, avec des têtes béantes et des étraves sculptées $»^{19}$.

La loi d'Úlfljót soulève deux éléments importants. D'une part, cette loi - qui constitue la nouvelle communauté - souligne qu'il est crucial, comme le témoigne la première place qui lui est assignée, pour les nouveaux venus de manifester un certain respect à l'égard des landvaettir s'ils veulent se maintenir durablement sur l'île. D'autre part, en tant qu'élément d'un code s'adressant spécifiquement aux Islandais (avec l'éventuelle addition des ressortissants de la métropole norvégienne qui maintinrent une relation privilégiée avec l'Islande «républicaine»), cette loi construit une identité basée sur la relation entre l'île, un groupe d'esprits et ses habitants «légitimes». C'est en effet pour ce groupe que la peur de ces êtres surnaturels pose problème. On est alors amené à se demander si un Islandais verrait d'un mauvais œil qu'un étranger naviguant sur un bateau équipé d'une figure de proue terrifiante et donc martiale effraie les landvattir. D'autres textes permettent d'apporter une

18. Au sujet de ces figures de proue, on consultera François-Xavier Dillmann, «Navigation et croyances magico-religieuses dans la Scandinavie ancienne. Quelques observations au sujet des figures de proue», Comptes-rendus des séances de l'Académie des Inscriptions et Belles-Lettres, 151, 2007, p. 383-420.

19. «Heyrði í Hafrsfirði,

hvé hizug barðisk

konungr enn kynstóri

við Kjọtva enn auðlagða;

knerrir kómu austan,

kapps of lystir,

með gínǫndum họfðum

ok grǫfnum tinglum. »

Texte cité à partir de l'édition en ligne du Skaldic Project: http://skaldic.arts. usyd.edu.au/db.php?if=default\&table=verses\&id=4339 (consulté le $1^{\text {er }}$ mars 2012). 
réponse à cette question et dévoilent la nature du comportement de ces êtres une fois effrayés.

\section{IV/ LA TERREUR DES LANDVETTIR}

Alors que Styrmir Kárason rédigeait sa version de la Landnámabók, Snorri Sturluson (1178-1241) utilisait les landvattir dans son Egils saga Skallagrímssonar (ou Saga d'Egil fils de Grím le chauve, c. 1230). Cette saga raconte les tribulations d'une famille norvégienne contrainte par les velléités centralisatrices du roi Harald à la belle chevelure (c. 850-933) de quitter ses terres ancestrales et d'émigrer vers l'Islande. Si la famille s'établit avec succès dans l'île, le héros éponyme Egil conserve toutefois des liens avec la métropole. Suite au décès de son beau-père, il se retrouve impliqué dans une querelle d'héritage en Norvège ${ }^{20}$. Or la querelle est d'autant plus difficile que son adversaire (son beau-frère qu'il accuse de captation d'héritage) a le soutient du roi Eirík et de la reine Gunnhild de Norvège - un conflit qui correspond, comme l'a démontré Lincoln, à celui qui oppose le droit coutumier à une monarchie en plein essor. Egil pour qui la loi est souveraine attaque en justice son beau-frère devant la cour du Gulaping. En effet, Egil dispose de témoins qui lui garantissent la victoire juridique. Toutefois, au moment où ceux-ci doivent être entendus par les juges, la reine donne l'ordre à des hommes armés de disperser le tribunal et empêche ainsi Egil de recevoir son dû légalement.

Egil réagit à cette démonstration de violence royale de plusieurs façons. Il tue son beau-frère et un fils du roi Eirík, mais il emploie également des moyens symboliques. En premier lieu, il maudit poétiquement le roi qui s'est montré coupable de mépris envers les lois et les assemblées (bing), une institution que la saga dote manifestement d'un caractère sacré, ainsi son aire est délimitée par des cordes tendues entre des piquets de noisetier appelées vébönd, littéralement «liens sacrés» :

Que les dieux le payent ainsi du pillage de mes biens: que les divinités chassent le prince des terres, qu'Odin et les dieux soient

20. Pour les enjeux légaux de ce cas, voir Bruce Lincoln, Authority: Construction and Corrosion, Chicago, 1994, p. 55-73. 
fâchés; que Freyr et Njörð fassent fuir de ses terres le tyran; que le dieu du pays se lasse de l'ennemi des hommes qui viole le sanctuaire ${ }^{21}$.

Exprimée dans le style ampoulé de la poésie scaldique, cette strophe se résume à appeler les dieux de la religion préchrétienne à chasser le roi du pays. En effet, elle met en évidence un principe territorial. Le poète demande non pas la mort ou le déshonneur, mais bien que celui qui a manqué de respect pour les espaces sacrés (vé) quitte l'espace du royaume. Egil invoque ainsi les dieux (goð, rögn et bönd signifient tous «dieux»)22. Parmi eux figurent Freyr, Njörð et Odin bien connus de la mythologie scandinave ainsi qu'un énigmatique landáss ( «dieu du pays» ou «dieu de la terre»; le terme est au singulier), dont le nom partage le même préfixe que les landvattir (au pluriel) ${ }^{23}$.

$\mathrm{Au}$ chapitre suivant, Egil donne voix à la même requête, cette fois formulée en prose et avec les landvattir pour agents:

Egil monta dans l'île [de Herðla]. Il prit un pieu de noisetier et alla sur un rocher qui regardait vers l'intérieur des terres. Il prit une tête de cheval et l'empala sur le pieu. Puis il déclama une formule et parla ainsi: «J'érige ici un pieu d'infamie, et je tourne cet outrage contre le roi Eirík et la reine Gunnhild», il tourna la tête de cheval vers les terres, - «je tourne cet outrage vers les landvattir qui habitent ce pays afin qu'ils aillent tous par de faux chemins, qu'ils n'atteignent et ne trouvent leur demeure avant qu'ils n'aient chassé du pays le roi Eirík et la reine Gunnhild.» Puis il planta le pieu dans une crevasse et le laissa

21. Egils saga Skallagrímssonar, éd. Sigurður Nordal, Reykjavík (Íslenzk Fornrit, II), 1933, p. 163: «Svá skyldi goð gjalda, gram reki bönd af höndum (reið sé rögn ok Óðinn) rán míns féar honum; folkmýgi lát flœja, Freyr ok Njörðr, af jörðum, leiðisk lofðastríði, landáss, panns vé grandar.»

22. Sur le lexique du terme «dieu», voir Maurice Cahen, Le mot «dieu» en vieux-scandinave, Paris, 1921.

23. Ce personnage est généralement interprété comme étant le dieu (áss) Thor: Jan de Vries, op. cit., t. 2, p. 357; Georges Dumézil, Les dieux des Germains. Essai sur la formation de la religion scandinave, Paris, 1959, p. 6. En revanche, Patricia Pires Boulhosa, «A *mitologia escandinava de Georges Dumézil: uma reflexão sobre método e improbabilidade», Brathair, 6/2, 2006, p. 16, propose que le landáss représente les landvattir. Cette équation, à la lumière de l'opposition entre singulier et pluriel et du fait que le substantif áss désigne normalement des dieux individuels personnels comme les trois mentionnés dans la strophe, me semble injustifiée. Pour le terme áss, voir Jan de Vries, article «Áss», Altnordisches etymologisches Wörterbuch, Leiden, 1977, p. 16. La strophe elle-même a été plusieurs fois traitées, outre les textes donnés ci-dessus, cf. Magnus Olsen, «Egils Viser om Eirik Blodøks og Dronning Gunnhild», Maal og Minne, 1944, p. 180200; Bo Almqvist, op. cit., t. 1, p. 89-118. 
là. Il tourna aussi la tête vers les terres et grava des runes sur le pieu, et elles répètent l'entier de cette formule ${ }^{24}$.

De toute évidence, la formule d'Egil joue avec la loi islandaise transmise par la Landnámabók en l'inversant. Alors que les Islandais devaient mettre à bas les têtes en Islande, Egil en élève une en Norvège (le terme utilisé dans les deux cas reste le même: höfuð) pour un effet diamétralement opposé. En Islande où ils sont légalement respectés, la cohabitation est aisée alors que la terreur des landvattir induite par Egil dans une Norvège où la loi est violée rend impossible toute cohabitation entre eux et le couple royal. Il est intéressant de noter que cette inversion est également présente dans l'effet paradoxal de cette terreur qui leur rend étrangère la terre (land) qu'ils habitent, tant qu'ils n'auront pas fait ce que demande Egil, à savoir chasser le roi hors de Norvège.

La saga donne une conclusion à cette opération rituelle. L'année suivante le couple royal est bien contraint d'abandonner la Norvège, une terre que le roi Eirík ne reverra plus. L'Egils saga reste délibérément ambiguë sur l'origine de ce départ forcé. Le chapitre LIX relate que, la même année, un rival à l'accession au trône arriva dans le royaume et réussit à lever davantage de troupes que le roi Eirík. Toutefois, la proximité textuelle entre les malédictions d'Egil et la fuite du roi en font une autre cause possible. Par conséquent, ce passage peut être lu comme une confirmation que l'occupation humaine d'un terroir était subordonnée au bon vouloir de ses landvattir, que ces derniers avaient les moyens de chasser les individus qu'ils considéraient comme ennemis, mais aussi que certains Islandais disposaient de la capacité d'influencer leur jugement. Ce dernier élément était absent des textes précédents, et il est possible que cette innovation propre à l'Egils saga soit liée à une autre. Si élever un pieu d'infamie (níðstöng) contre quelqu'un

24. Egils saga, op. cit., p. 171: «[G]ekk Egill upp í eyna. Hann tók í hönd sér heslisstöng ok gekk á bergnös nökkura, pá er vissi til lands ; pá tók hann hrosshöfuð ok setti upp á stöngina. Síðan veitti hann formála ok mælti svá: "Hér set ek upp níðstöng, ok sný ek pessu níði á hönd Eiríki konungi ok Gunnhildi dróttningu," hann sneri hrosshöfðinu inn á land, - "sný ek pessu níði á landvættir pær, er land petta byggva, svá at allar fari pær villar vega, engi hendi né hitti sitt inni, fyrr en pær reka Eirík konung ok Gunnhildi ór landi." Síðan skýtr hann stönginni niðr í bjargrifu ok lét par standa; hann sneri ok höfðinu inn á land, en hann reist rúnar á stönginni, ok segja pær formála penna allan. » Sur Egil, on consultera FrançoisXavier Dillmann, op. cit., p. 128 sq. 
est une pratique bien connue d'autres textes islandais, danois ou anglais ${ }^{25}$, cette saga est l'unique occurrence où de tels pieux sont liés aux landvattir. Or il semblerait que cet ajout soit tout sauf innocent. En effet, l'ennemi est ici un roi qui a failli en tous points: profanateur des assemblées, irrespectueux du droit coutumier et plus important encore, ennemi du héros islandais dont la saga fait le porte-parole des valeurs politiques islandaises, en premier lieu par son opposition à l'institution royale. Les landvattir sont présentés dans ce texte comme des gardiens du code moral, concrétisé par ses expressions collectives que sont la loi et les assemblées, et contre un système politique, la royauté centralisée et autocrate. Si leur intervention dans la saga peut être comprise comme un artifice servant à ancrer le récit dans la période préchrétienne, leur présence n'est pas à mettre strictement au compte d'un souci de vraisemblance historique. L'Egils saga Skallagrímssonar suggère ainsi que les landvattir pouvaient être utilisés pour traiter de questions intéressant le XIII ${ }^{\mathrm{e}}$ siècle chrétien.

Lorsque les témoignages de la Landnámabók et de l'Egils saga sont rassemblés systématiquement, il devient tentant de conclure que l'île de l'Atlantique nord était représentée, et cela dès la période préchrétienne, comme défendue par de puissants gardiens surnaturels qui refoulaient ceux qui les menaçaient - notamment les flottes de guerre équipées de têtes menaçantes - et favorisaient sa population légitime. Ces gardiens étaient nécessaires à une île

25. Pour un exemple islandais, voir le chap. xxxiv de la Vatnsdoela saga, éd. Einar Ól. Sveinsson, Reykjavík (Íslenzk Fornrit,vIII), 1939, p. 91. Saxo Grammaticus (1150-1220), l'auteur danois des Gesta Danorum, parle d'un obscenitatis apparatum (livre v, III.2) - une tête de cheval plantée sur un pieu dont la bouche est maintenue ouverte (Peter Fisher et Hilda Ellis Davidson, Saxo Grammaticus: The History of the Danes, Cambridge, 1979, p. 128). Bruce Lincoln, op. cit., p. 192 mentionne un procès anglais qui nous apprend que «a group of poachers who had taken three deer cut off the head of a buck and put it on a stake in the middle of a certain clearing, placing in the mouth of the aforesaid head a certain spindle; and they made the mouth gape towards the sun, in great contempt of the lord king and of his foresters», cf. Select Pleas of the Forest, éd. George Turner, London, 1901, p. 38-40. Le pieu d'infamie et sa contrepartie verbale, le níð, (insultes rituelles, parfois poétiques, qui mobilisent volontiers des thèmes sexuels), ont été le sujet de nombreuses études, par exemple Bo Almqvist, op. cit.; Folke Ström, Níð, Ergi, and Old Norse Moral Attitudes, London, 1974, p. 4 ; Preben Meulengracht Sørensen, The Unmanly Man: Concepts of Defamation in Early Norse Society, Odense, 1983; Kari Gade, «Homosexuality and the Rape of Males in Old Norse Law and Literature», Scandinavian Studies, 58, 1986, p. 124-141. 
sans armée (l'île étant d'ailleurs constitutionnellement dépourvue de pouvoir exécutif centralisé ${ }^{26}$. Cependant, leur efficacité fut peu mise à l'épreuve: la très longue distance de haute mer et les côtes dangereuses de l'Islande rendirent longtemps l'éventualité d'une invasion relativement peu crédible.

\section{V/ Un DISCOURS ANTIMONARCHIQUE}

La date de l'apparition des landvattir dans les sources norroises est un problème très peu discuté. Clunies Ross considère les récits traités ci-dessus comme des témoins fiables des représentations préchrétiennes scandinaves. Mais est-ce bien le cas? Quand apparaissent-ils? S'ils appartenaient effectivement aux représentations préchrétiennes, ont-ils conservé un profile identique entre le $\mathrm{IX}^{\mathrm{e}}$ et le $\mathrm{XIII}^{\mathrm{e}}$ siècles? Sur la base de la documentation disponible, ils n'apparaissent explicitement que plus de deux cent ans après la conversion, autour de 1220, lorsque Snorri Sturluson composait son Egils saga et Styrmir Kárason, suivi une génération plus tard par Sturla Pórðarson, s'appliquait à étoffer les traditions généalogiques des versions les plus anciennes de la Landnámabók ${ }^{27}$. Une recherche dans la base de données du projet Skaldic Poetry of the Scandinavian Middle Ages indique en effet que ce substantif n'était pas connu de la poésie scaldique, dont une partie remonte indubitablement à la période préchrétienne ${ }^{28}$. Ainsi, si on se limite à ses énoncés poétiques susceptibles d'être réellement anciens, soit Egil Skallagrímsson ne les connaissait pas ou bien n'y trouvait-il guère d'intérêt dans le cadre de son conflit avec le roi Eirík. Tout au plus fit-il mention de ce landáss («dieu de la terre», dans un sens restreint), un substantif qui a pu mener le rédacteur de la saga, au XIII ${ }^{\mathrm{e}}$ siècle, à intégrer les landvattir à son récit. Quel crédit peut-on

26. Sur l'organisation politique de l'Islande, voir par exemple William Ian Miller, Bloodtaking and Peacemaking: Feud, Law, and Society in Saga Iceland, Chicago, 1990; Jón Viðarr Sigurðsson, Chieftains and Power in the Icelandic Commonwealth, Odense, 1999; Orri Vésteinsson, The Christianization of Iceland: Priests, Power, and Social Change 1000-1300, Oxford, 2000 ; Jesse Byock, Viking Age Iceland, Harmondsworth, 2001; Richard Gaskins, «Network Dynamics in Saga and Society», Scandinavian Studies, 77/2, 2005, p. 201-216.

27. Voir Jonas Wellendorf, art. cit., p. 4.

28. http://skaldic.arts.usyd.edu.au/db.php (consulté le 5 juillet 2012). 
dès lors accorder à ces textes en tant que sources pour les croyances préchrétiennes? Plutôt que de m'attacher à ce problème, il semble plus pertinent de traiter ces textes comme des discours parlant de, et à, leur situation de communication.

La décennie s'étalant de 1220 à 1230 est importante dans le contexte présent car elle représente un tournant majeur dans l'histoire politique de l'Islande. Le siècle précédent avait vu de violentes guerres civiles en Norvège. Ces conflits s'accompagnèrent de l'introduction de la sanction divine pour le monarque norvégien ${ }^{29}$ et de l'établissement par le roi Sverrir Sigurðarson (r. 1177-1202) d'une force militaire professionnelle qui eut pour effet d'améliorer la base économique de la couronne, notamment en rendant plus efficace la collecte des impôts. Ainsi, entre la fin du $\mathrm{XII}^{\mathrm{e}}$ et le XIII ${ }^{\mathrm{e}}$ siècles, la Norvège devint un état centralisé dont le chef royal monopolisait de plus en plus l'exercice de la justice, l'usage de la violence, etc.; processus qui selon Lincoln est (anachroniquement) décrit et dénoncé par l'Egils saga ${ }^{30}$.

Lorsque le petit-fils de Sverrir, Hákon Hákonarson (1204-1263) accéda au trône en 1217 , la couronne était suffisamment puissante pour résister aux velléités insurrectionnelles et tourner son attention vers l'extérieur. Déjà sous Sverrir, des régions périphériques (le Jämtland en Suède actuelle, les Orcades et les Shetlands) avaient été entrainées dans l'orbite norvégienne ${ }^{31}$. Autour de 1220, le roi Hákon

29. Le roi en question est Magnús Erlingsson, couronné par Eystein Erlendsson, archevêque de Niðaróss (l'actuelle Trondheim) soit en septembre 1163 soit pendant l'été 1164, voir le chap. XXII de la Magnúss saga Erlingssonar (in Heimskringla, III, éd. Bjarni Aðalbjarnarson, Reykjavík (Íslenzk Fornrit, XXVIII), 1951, p. 397-398); et le chap. cix de la Fagrskinna (in Ágrip af Nóregskonunga Sögum, éd. Bjarni Einarsson, Reykjavík (Íslenzk Fornrit, XXIX), 1984, p. 351). Sur ce couronnement, voir Kevin Wanner, «At Smyrja Konung til Veldis: Royal Legitimation in Snorri Sturluson's Magnúss saga Erlingssonar», Saga-Book, 30, 2006, p. 5-38.

30. Voir Bruce Lincoln, op. cit., p. 68-69. Pour la construction de l'état norvégien et plus généralement en Scandinavie, voir, par exemple, Knut Helle, Norge blir en Stat, Bergen, 1974; Sverre Bagge, From Gang Leader to the Lord's Anointed: Kingship in Sverris Saga and Hákonar Saga Hákonarsonar, Odense, 1996; Klaus von See, Königtum und Staat im skandinavischen Mittelalter, Heidelberg, 2002; Jón Viðarr Sigurðsson, «Tendencies in the Historiography on the Medieval Nordic State (to 1350) », in James Amelang and Siegfried Beer (dir.), Public Power in Europe: Studies in Historical Transformations, Pisa, 2006, p. 1-15; Bruce Lincoln, Between History and Myth: Stories of Harald "Fairhair" and the Founding of the State, à paraître.

31. Voir Knut Helle, «The Norwegian Kingdom: Succession Disputes and Consolidation », in Idem (dir.), The Cambridge History of Scandinavia : Prehistory to 1520, Cambridge, 2003, p. 369-391. 
commença à manifester ouvertement ses desseins impérialistes sur l'Islande. La politique étrangère de Hákon est longuement décrite dans sa biographie, une saga écrite par son contemporain islandais Sturla Pórðarson qui passa une partie de sa vie à la cour et rédigea l'une des versions de la Landnámabók. Sturla raconte à la fois dans la Hákonar saga Hákonarsonar ${ }^{32}$ (ou Saga du roi Hákon Hákonarson) et dans son Íslendinga saga ${ }^{33}$ (ou Saga des Islandais) une séquence d'événements qui dans le contexte présent est lourde de conséquences. En 1215, le chef islandais Sæmund Jónsson fixe les prix des marchandises de Norvégiens à leur grand déplaisir. L'année suivante, à Bergen, son fils Pál se fait en représailles si copieusement insulter qu'il quitte précipitamment la ville pour Trondheim et se noie pendant la traversée. En 1217, Sæmund, qui tient les Norvégiens pour responsables de la mort de son fils, se venge en imposant des amendes à des marchands, ce qui sera suivi en 1218 du meurtre de son frère Orm. Finalement la couronne s'en mêle et, en 1220, le régent du jeune Hákon annonce qu'il va armer une flotte pour aller punir l'Islande.

Comment les Islandais dépourvus de roi et d'armée pouvaientils se prémunir contre une telle menace? Parmi les réponses stratégiques que donnèrent les Islandais, figuraient les landvattir. Un dernier texte illustrera cette réponse discursive. Rédigée dans les années qui suivent directement cette querelle commerciale, l'Óláfs saga Tryggvasonar ${ }^{34}$ (ou Saga du roi Óláf Tryggvason) propose un passage qui - bien que traitant de la deuxième moitié du $\mathrm{X}^{\mathrm{e}}$ siècle - peut être lu comme un commentaire sur ces événements contemporains. Le chapitre XXXIII de la saga s'ouvre avec le naufrage d'un navire islandais sur les côtes de Danemark. Au mépris du droit, le roi Harald Gormsson de Danemark s'empare de sa cargaison. Excédés par cette démonstration d'arbitraire royal,

32. Hákonar saga, chap. xxxvIII sq. (in Icelandic Sagas and Other Historical Documents Relating to the Settlements and Descents of the Northmen on the British Isles, éd. Guðbrandur Vigfússon, London, 1887, t. 2, p. 37 sq).

33. Íslendinga saga, chap. XL-XLIII (in Sturlunga Saga including the Islendinga Saga of Lawman Sturla Thordsson and Other Works, éd. Guðbrandur Vigfússon, Oxford, t. 1, p. 236-243).

34. L'Óláfs saga Tryggvasonar fait partie de la vaste compilation de biographies de rois norvégiens intitulée Heimskringla. Les spécialistes tendent à l'attribuer à Snorri Sturluson. Sur l'épisode dont il sera question ici, voir Bo Almqvist, op. cit., p. 119 sq. L'édition utilisée ici est Heimskringla I, éd. Bjarni Aðalbjarnason, Reykjavík (Íslenzk Fornrit, XXvi), 1941. 
les Islandais promulguent une loi exigeant de chaque habitant qu'il compose une strophe outrageante (níðvísa) au sujet du roi ${ }^{35}$. Peu de temps après, alors qu'il guerroie en Norvège, le roi décide de prolonger son expédition vers l'Islande. Toutefois, il décide d'envoyer préalablement un éclaireur, un homme aux pouvoirs magiques qui se transforme en baleine et va reconnaître l'île. Arrivé en vue de l'île:

Il vit que toutes les montagnes et les collines étaient pleines de landvattir, certains grands, certains petits. Et lorsqu'il arriva au Vápnafjord, il entra dans le fjord pensant aller à terre. Mais alors un grand dragon descendit de la vallée et il était suivi de nombreux serpents, crapauds et vipères et ils crachèrent du venin sur lui; mais il s'enfuit vers l'ouest jusqu'à l'embouchure de l'Eyjafjord. Il alla le long de ce fjord, mais un oiseau si grand que ses ailes touchaient la montagne des deux côtés alla contre lui avec une foule d'autres oiseaux, grands et petits. Il parti vers l'ouest le long de la terre puis vers le sud dans le Breiðafjord et y entra. Un grand taureau s'avança contre lui dans la mer et se mit à mugir terriblement. Une foule de landvattir le suivait. Il repartit vers le sud, passa le Reykjanes et voulut accoster sur Víkarsskeið. Un géant des montagnes qui tenait un bâton de fer s'avança contre lui, sa tête dépassait les montagnes et beaucoup de géants allaient avec lui. Il repartit vers l'est en longeant la côte ${ }^{36}$.

35. Óláfs saga, chap. xxxIII (in Heimskringla, op. cit., p. 270) n'en donne qu'une strophe. Celle-ci contient la périphrase (kenning) bergsalar böndum («dieux de la salle de la montagne»). Or le poème demande à ces derniers de chasser l'intendant du roi danois de la terre. La référence de cette kenning est obscure et il est même possible que le complément d'objet dépende d'un autre nom (cf. Ernst Kock, Notationes norræna. Anteckningar till Edda och skaldediktning, Lund, 1923-44, § 1092 qui voyait bergsalar landi, «terre de la salle de la montagne», i.e. Norvège). Certains savants dont Sveinbjörn Egilsson, Lexicon poëticum antiquce lingua septentrionalis, Copenhagen, 1860, s. v. ou François-Xavier Dillmann, Histoire des rois de Norvège par Snorri Sturluson, Paris, 2000, p. 537, ont interprété bergsalar böndum par landvattir. Toutefois, une telle interprétation ne trouve pas de soutien textuel autre que l'épisode de la tête de cheval dans l'Egils saga. Or, si analogie il y a avec cette saga, c'est bien avec la malédiction poétique qui fait état de choix lexicaux semblables (Óláfs saga: «Birgir rækr böndum bergsalar í landi », "Birgir chassé par les dieux de la salle de la montagne dans la terre"; Egils saga: "gram reki bönd af löndum», "que les dieux chassent le prince des terres"), où ceux qui chassent sont bien les dieux personnels de la mythologie norroise, Odin, etc.

36. Óláfs saga, chap. XXXIII (in Heimskringla, op. cit., p. 271): «Hann sá, at fjöll öll ok hólar váru fullir af landvéttum, sumt stórt, en sumt smátt. En er hann kom fyrir Vápnafjörð, pá fór hann inn á fjörðinn ok ætlaði á land at ganga. Pá fór ofan eptir dalnum dreki mikill, ok fylgðu honum margir ormar, pöddur ok eðlur ok blésu eitri á hann. En hann lagðisk í brot ok vestr fyrir land, allt fyrir Eyjafjörð. Fór hann inn eptir beim firði. Par fór móti honum fugl svá mikill, at vængirnir tóku út fjöllin tveggja vegna, ok fjölði annarra fugla, bæði stórir ok smáir. Braut fór hann 
Ayant ainsi été repoussé de l'Islande par les landvattir, le magicien confirme au roi danois l'impossibilité de s'attaquer à l'île par des considérations pratiques (la distance et les côtes dangereuses). Le roi abandonne donc son projet et rentre au Danemark. En guise d'épilogue, la saga mentionne les noms des chefs des quatre régions visitées par le magicien (régions qui correspondent aux quatre quartiers administratifs de l'île) et, au cas où la correspondance entre le dragon, l'oiseau, le taureau et le géant ${ }^{37}$ et les quatre chefs ne frapperait pas immédiatement le lecteur, le texte indique que le troisième - contrepartie du taureau mugissant (inf. gella) - avait pour surnom gellir (lit. «celui qui mugit»). Cette dernière précision suggère que la symbiose entre l'île et ses habitants est telle, que leur possession de cette terre est si «naturelle» ou «légitime», qu'ils peuvent mobiliser ses gardiens surnaturels. Ainsi, la communauté humaine ou plutôt ses chefs, bien loin de dépendre du bon plaisir des landvattir, ont le pouvoir de diriger leur violence contre leurs propres ennemis. Ce texte, destiné à un lectorat royal, met en évidence la capacité de l'Islande à se défendre des agressions royales par l'intermédiaire des landvattir, et peut ainsi être lu comme un avertissement pour tout roi, Hákon compris, qui serait tenté par une opération navale ${ }^{38}$.

paðan ok vestr um landit ok svá suðr á Breiðafjörð ok stefndi par inn á fjörð. Par fór móti honum griðungr mikill ok óð á sæinn út ok tók at gella ógurliga. Fjölði landvétta fylgði honum. Brot fór hann paðan ok suðr um Reykjanes ok vildi ganga upp á Víkarsskeiði. Par kom í móti honum bergrisi ok hafði járnstaf í hendi, ok bar höfuðit hæra en fjöllin, ok margir aðrir jötnar með honum. Paðan fór hann austr með endlöngu landi.»

37. Ces quatre figures ne vont pas sans rappeler le tétramorphe chrétien: Matthieu représenté par un homme, Marc par un lion, Luc un taureau et Jean un aigle; cf. Ez. 1, 10 et Apoc. 4, 7. Bien que lion et dragon ne soient pas identiques, peu de commentateurs ont manqué de voir cette correspondance, qui confère à ces landvattir une certaine sanction chrétienne. Le premier savant à discuter cette correspondance fut Matthías Porðarson, Pjóðmenjasafn Íslands, Reykjavík, 1914, p. 8.

38. Bo Almqvist arriva à une interprétation semblable mais n'osa en tirer les conséquences: "One would have to take into consideration that certain traits have been inserted in order to serve Snorri's patriotic intentions, but it is not found probable that Snorri would, of his own accord, make up a tale as loaded with fantastic traits as our episode », Almqvist, op. cit., p. 224, voir aussi p. 130 sq. Par conséquent, Snorri devient un antiquaire transmettant des traditions mythologiques ou folkloriques plutôt qu'un acteur réagissant textuellement à un contexte extratextuel, une vision récemment déconstruite par Kevin Wanner, Snorri Sturluson and the Edda: The Conversion of Cultural Capital in Medieval Scandinavia, Toronto, 2008. 
À la manière de l'Egils saga, le chapitre xxxiII de l'óláfs saga propose des informations inconnues de toute autre version médiévale de ces événements. Ainsi, le chapitre XIII de la Jómsvíkinga saga (ou Saga des Vikings de Jómsborg), dans la version préservée par le manuscrit AM 291 4to (deuxième moitié du XIII ${ }^{\mathrm{e}}$ siècle), narre la même expédition norvégienne de Harald Gormsson, mais propose une version différente ${ }^{39}$. Si le roi y envisage également d'envoyer une force en Islande pour se venger de strophes outrageantes, il se rend compte cette fois rationnellement que la vaste étendue d'océan rend une telle expédition fort dangereuse. La Jómsvíkinga saga ne fait donc mention ni du magicien ni des landvattir ${ }^{40}$. De plus, le texte décrit la réaction islandaise à cette menace royale par une strophe qui appelle à une résistance armée d'un type purement mondain:

Que personne ne vende d'arme pour de l'argent, qu'il y ait vacarme d'épées (i.e. «bataille») si cela doit arriver, nous devons durcir le bruit de Hroptr (i.e. «bataille»), nous devons rougir les armes; nous allons attendre dans la vieille terre de brume de Gandvík (i.e. «l'Islande») le fils de Gorm (i.e. Harald) - on s'attend à une dure tempête d'armes $(\text { i.e. «combat» })^{41}$.

Si cette strophe est authentiquement ancienne, elle suggère qu'au $\mathrm{X}^{\mathrm{e}}$ siècle la communauté islandaise, lorsqu'elle se trouva face à la menace d'une invasion navale, ou bien ne se connaissait pas de tels gardiens ou n'éprouva pas le besoin de se doter de tels défenseurs.

Par ailleurs, des textes qui s'appuient directement sur l'óláfs saga de Snorri présentent des différences considérables. Bien que son rédacteur fût un Islandais - peut-être Óláf Pórðarson, un neveu de Snorri - la Knýtlinga saga (ou Saga des descendants de Knut le grand) était destinée à un lectorat danois et adopte par conséquent

39. Pour une discussion des problèmes philologiques de cette saga, voir N. F. Blake, Jómsvíkinga Saga. The Saga of the Jómsvikings, London, 1962, p. Xv-Xx.

40. Jómsvíkinga saga, chap. XIII : «Haraldr konungr tók pat ráð, sem ván var, er margir spakir menn véltu umb, sem bezt gegndi, vendi nú aptr suðr til Danmerkr», cité in Bo Almqvist, op. cit., p. 122.

41. «Selit maðr vápn við verði,

verði dynr ef má sverða,

verðum Hropts at herða

hljóð; eigum slög rjóða ;

vér skulum Gorms af gömlu

Gandvíkr poku landi

(hörð es vön at verði

vápnhríð) sonar bíða.» (Den Norsk-Islandske Skjaldedigtning, éd. Finnur Jónsson, Copenhague, 1910, t. B-II, p. 95). 
une perspective résolument danoise (celle du roi Harald Gormsson). Évidemment, cela exigeait l'altération de la portée idéologique de la défense surnaturelle de l'île:

Le roi Harald resta un moment avec son armée dans les Sólundir [dans le Sogn en Norvège occidentale] avec l'intention de dévaster l'Islande avec son armée. Il voulait se venger des poèmes insultants que les Islandais avaient composés pour lui faire honte. Le roi Harald ordonna à un magicien d'aller sous forme animale en Islande et de voir ce qu'il pourrait en dire au roi. Il alla sous forme de baleine autour du pays puis dit au roi que beaucoup de monstres pratiquant la magie habitaient ce pays et que la mer entre les terres était si large que des navires de guerre ne pourraient la franchir. Lorsque le roi Harald apprit cela, il crut comprendre que c'était extrêmement dangereux et que ce ne serait pas possible de l'accomplir ${ }^{42}$.

Outre bien des omissions, la Knýtlinga saga remplace le terme landvaettir par celui d'óvattir avec de graves conséquences puisque ce dernier est absolument péjoratif. Óvattir ne dénote pas une catégorie particulière d'êtres mais signifie génériquement «monstres» ou «esprits malfaisants» ${ }^{43}$. Le texte abandonne les landvattir puisque ceux-ci servent un argumentaire inadapté à une célébration de la maison royale de Danemark. Vus de Danemark, les êtres qui repoussent l'éclaireur ne sauraient être des protecteurs; ce sont des monstres qui pratiquent la sorcellerie et habitent une île perdue aux confins du globe. À la lumière de ces permutations, il apparaît bien que les irruptions textuelles des landvattir représentent l'aboutissement de choix stratégiques par les rédacteurs de sagas, leur nature et présence (ou absence) discursives étaient dictées par des situations spécifiques : par exemple la menace que l'impérialisme norvégien faisait peser sur l'Islande républicaine à partir de 1220 .

Affirmer que les landvattir sont une création du XIII ${ }^{\mathrm{e}}$ siècle serait exagéré. Il ne fait pas de doute que ces êtres mythologiques furent

42. Knýtlinga saga, chap. III (in Danakonunga Sögur, éd. Bjarni Guðnason, Reykjavík (Íslenzk Fornrit, Xxxv), 1982, p. 96) : «Haraldr konungr lá um hríð með her sinn í Sólundum ok ætlaði pá at herja til Íslands með liði pví, er hann hafði par, ok vildi hann hefna níðs pess, er Íslendingar höfðu gört um hann ok níddan hann. Haraldr konungr bauð kunnigum manni at fara í hamförum til Íslands ok vita, hvat hann kynni paðan at segja konungi. Sá fór í hvalslíki umhverfis landit ok sagði síðan konungi, at margar kunnigar óvættir byggva pat land, en haf svá mikit milli landanna, at pat var ekki fort langskipum. Ok er Haraldr konungr varð pessa varr, pá póttisk hann skilja, at petta var in mesta ófœra, ok ekki mátti pessu til leiðar koma.»

43. Voir Richard Cleasby, Guðbrandur Vigfússon et William Craigie, article «úvattr», An Icelandic-English Dictionary, Oxford, 1957, p. 667. 
connus de la Scandinavie préchrétienne ainsi que le suggère la littérature aussi bien législative qu'homilétique. Toutefois, j'estime que leur rôle discursif de gardiens de l'île, capables de repousser ou de chasser les rois injustes et agressifs, a dû être particulièrement attrayant pour une Islande confrontée à une couronne qui, avec le roi Hákon Hákonarson, devenait suffisamment centralisée et puissante pour rendre crédible la menace d'une expédition navale transatlantique. Leurs apparitions dans des textes écrits entre les années 1220 et 1240 ne peuvent par conséquent pas être traitées comme le produit d'un travail objectif d'érudit antiquaire.

Le lecteur pourrait être tenté de conclure de ce qui précède que les discours religieux ou mythologiques sont des réponses efficaces aux problèmes politiques, que la plume est plus forte que l'épée. Toutefois, les événements historiques mentionnés ici trouvent un épilogue quelque peu pathétique. Sturla Pórðarson, dans son Íslendinga saga qui offre une chronique des agissements des Islandais entre 1183 et 1262, explique autrement la manière dont l'Islande échappa à l'invasion en 1220. L'Islandais indique que, lorsque le roi réfléchissait à cette expédition, son oncle Snorri Sturluson, l'auteur de l'Egils saga et de l'Óláfs saga, se trouvait à la cour. Le chapitre XXXVIII de l'Íslendinga saga indique alors que:

Snorri déconseilla fortement de mettre à exécution l'expédition. Il conseilla de s'attacher les meilleurs hommes d'Islande; et il affirma qu'il arriverait rapidement par ses mots à faire en sorte qu'il semble adéquat aux gens d'accepter l'autorité des chefs de Norvège ${ }^{44}$.

Ainsi, selon Sturla - dont la version de la Landnámabók omet la loi exigeant le retrait des figures de proue - ce ne fut pas par peur des gardiens surnaturels de l'île que le roi renonça à la violence. Il voyait bien qu'obliger les grands d'Islande à œuvrer pour lui serait plus efficace et plus aisé que de conduire une expédition militaire hasardeuse à travers l'Atlantique nord ${ }^{45}$. Et si Snorri ne fit rien pour favoriser la cause du roi dans l'île, il s'en trouva d'autres pour servir Hákon. Entre 1262 et 1264, l'île devenait la vassale de la Norvège.

44. Sturlunga Saga, op. cit., p. 243: «Snorri latti mjök ferðarinnar. Ok kallaði pat ráđ at göra sér at vinum ina beztu menn á Íslandi ; ok kallaðisk skjótt svá mega koma sínum orðum, at mönnum mundi sýnask at snúask til hlýðni við Noregshöfðingja.»

45. Voir Theodore Andersson, «The King of Iceland», Speculum, 74, 1999, p. 925-934, en particulier p. 928 . 


\section{VI/ LES LANDVAETTIR DE LA RÉPUBLIQUE D'ISLANDE}

Que les discours religieux ou mythologiques présentent des solutions privilégiées aux problèmes politiques, nonobstant d'éventuels ratés, est illustré par la pérennité du mythe des landvaettir protégeant l'Islande dans les consciences islandaises. Un peu moins de sept siècles après son annexion par Hákon, le premier décembre 1918, l'île devenait à nouveau un état souverain, bien qu'en union personnelle avec le royaume de Danemark. Deux mois plus tard, l'Islande reflétait ce changement en modifiant ses armoiries qui se composaient alors d'azur au faucon d'argent. Un décret royal fut émis en consultation avec des historiens et philologues, dont Matthías Pórðarson qui publia des travaux sur les landvattir ${ }^{46}$, stipulant que: "Les armoiries d'Islande seront un écu chargé du drapeau de l'Islande surmonté d'une couronne. Les supports de l'écu sont les quatre esprits gardiens bien connus du pays: un dragon, un vautour, un taureau et un géant $\gg^{47}$. Lorsque la république fut proclamée le 17 juin 1944 - une proclamation à laquelle des philologues comme Sigurður Nordal (1886-1974) n'étaient pas étrangers ${ }^{48}$ - les armoiries furent maintenues à l'exception de la couronne. À cette occasion, elles reçurent un nouveau dessin exécuté par Tryggvi Magnússon.

46. Cf. note 37.

47. Birgir Thorlacius, A Brief History of the Icelandic Coat of Arms, disponible en ligne: http://eng.forsaetisraduneyti.is/state-symbols/icelandic-coat-of-arms/ history/\#Guardian_spirits (consulté le 27 juin 2012).

48. Nordal, éditeur en chef de la prestigieuse série d'éditions de sagas Íslenzk Fornrit entre 1933 et 1951, joua un rôle politique actif dans son pays, notamment en tant qu'ambassadeur au Danemark entre 1951 et 1957. Jesse Byock, Medieval Iceland: Society, Sagas, and Power, Berkeley, 1988, p. 41-48, a attiré l'attention sur le lien entre nationalisme islandais et le courant de critique littéraire appelé Buchprosa dont Nordal fut le champion. Ce courant est principalement connu pour son affirmation de l'origine écrite (et donc strictement islandaise) des sagas. À l'image des frères Grimm ou d'Elias Lönnrot, compilateur du Kalevala, ses partisans dotaient l'Islande du XIII ${ }^{\mathrm{e}}$ siècle d'une littérature et d'auteurs dignes des plus grandes nations. Byock indique ainsi que: «The literary basis of the sagas equipped Iceland with a cultural heritage worthy of its status as an independent nation» (Jesse Byock, Medieval Iceland, op. cit., p. 46). Sur Nordal, voir Ármann Jakobsson, article «Nordal», Reallexikon der germanischen Altertumskunde, t. 21, Berlin, 2002, p. 269-271. 


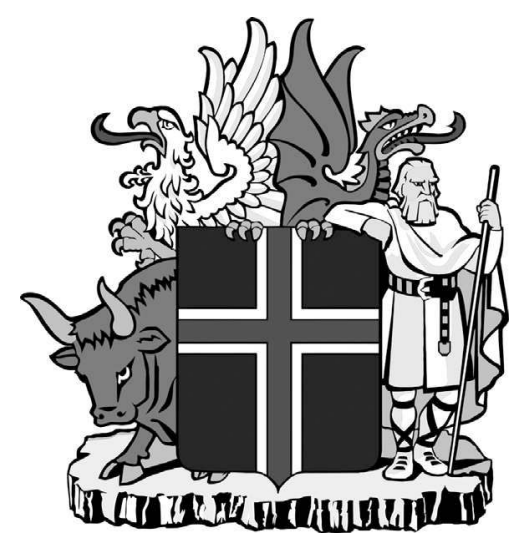

Fig. 1: Les armoiries d'Islande, dessin de Tryggvi Magnússon, $1944^{49}$

Le même jour, le président nouvellement élu Svein Björnsson fit la déclaration suivante:

Les armoiries de l'Islande sont une croix d'argent dans un champ d'azur, avec une croix de gueules dans la croix d'argent. Les bras de la croix se prolongeront jusqu' au bord de l'écu sur les quatre côtés. [...]

Les supports sont les quatre esprits gardiens de l'Islande tels que la Heimskringla les décrit [i.e. au chap. XXXIII de l'óláfs saga]: un taureau à la droite de l'écu; un géant à gauche; un oiseau à droite au-dessus du taureau; et un dragon à gauche au-dessus du géant.

L'écu repose sur une terrasse de basalte ${ }^{50}$.

De même, la monnaie de l'île (qui, ironiquement, se nomme «couronne», króna) porte une représentation des landvattir. Les quatre figures surnaturelles qui avaient chassé le magicien du roi danois ont donc à nouveau été mobilisées pour du service de garde. Ils avaient peut-être échoué à protéger l'Islande du roi de Norvège, mais ils offrirent à l'Islande un discours identitaire d'autosuffisance qui s'empara si profondément des consciences que des siècles plus tard les landvattir devenaient les gardiens «naturels » de la sécurité politique et financière de l'île.

nicolas.meylan.2@unil.ch

Institut religions, cultures, modernité

Université de Lausanne

CH-1015 Lausanne

49. http://eng.forsaetisraduneyti.is/state-symbols/icelandic-coat-of-arms/ history/ (consulté le 5 juillet 2012).

50. Thorlacius, op. cit. 